\title{
Two-way Evaluation and Analysis of Student-centered Pharmacy Teaching
}

\author{
Lijuan Cheng \\ Yichun Vocational Technology College, Yichun 336000, China \\ 20175490@qq.com
}

\begin{abstract}
Student-centered teaching model is a very important concept in the education sector, which will be restricted and influenced by many factors in the process of implementation. This paper focuses on investigating and studying the influence of teachers, students and supporting management of teaching reform on this teaching mode. According to undergraduates in pharmacy department of our hospital, the whole class was divided into study group and control group. Twoway evaluation method was used in the study group, and traditional experimental teaching method was used in the control group. The experimental theory, skill test scores and experimental report scores of the two groups of students were compared and analyzed, and the evaluation of teachers' teaching methods and learning effects of the students in the study group were investigated. The results show that students' evaluation of the Two-way evaluation method and teaching effect are very good. Two-way evaluation can stimulate students' interest in learning, and help to cultivate students' awareness of inquiry, practical ability, innovative ability, ability to analyze and solve problems.
\end{abstract}

Keywords: Take Students as the Main Body; Two-way Evaluation; Bidirectional Evaluation.

\section{Introduction}

Pharmacy is a comprehensive applied technical science that studies the prescription design, basic theory, production technology, quality control and rational application of preparations. It is also a major specialized course of pharmacy. Because pharmacy is a practical and applied subject, experimental teaching is very important to cultivate students' professional ability. As an independent subject, pharmacy has its own research mode and method, and students need basic skills training to master this course smoothly.

Teaching evaluation is an important mechanism and means of teaching quality control. The scientific rationality of the system will ultimately affect the quality of personnel training [1]. In order to promote the teaching quality of traditional Chinese medicine preparation analysis, the author implemented the Two-way evaluation method in the teaching process. Emphasis on students as the main body. Find problems and seek solutions in active learning [2]. Form a three-dimensional knowledge network to solve problems, and organize and guide students to complete tasks. In the whole teaching process, students and teachers constantly adjust their goals to complete the course with high quality.

\section{Analysis of Influencing Factors of Student-centered Teaching Model}

\subsection{Student Factors}

The new Student-centered teaching model requires students to participate in teaching activities, focusing on the process of students' participation in learning and emphasizing creative problem solving [3]. On the one hand, students should actively participate in classroom teaching; on the other hand, outside classroom teaching, they should spend more time and energy to consult various materials for self-study, take advantage of various opportunities to participate in social practice, and conduct on-the-spot investigation and research. All these require students to take the initiative to make use of the extremely rich teaching resources in the society, and conduct self-learning in various ways and through various channels. 
This requires students not only to have strong self-study ability and analysis and summary ability, but also to have certain social activity ability. Therefore, the level of students' participation ability will affect the effect of teaching reform.

\subsection{Teachers' Factors}

In the new Student-centered teaching mode, students' participation in the teaching process has been brought into full play. Teachers will ask students many questions in class, but students will also ask many unexpected questions [4]. These problems may not only be not considered by teachers when preparing lessons, but also are knowledge not included in textbooks at all. This kind of problem often puts teachers in a passive situation, and it is very likely that the original prepared teaching content and planned teaching progress cannot be carried out.

This reduces the controllability and predictability of curriculum teaching, and greatly increases the difficulty for teachers to control curriculum teaching. Therefore, teachers are required to have higher ability to control curriculum teaching.

\subsection{Factors in the Reform of Teaching Management}

The core of Student-centered teaching mode is that students actively participate in the whole process of teaching, and a very important part is that students actively explore and verify their knowledge to achieve the purpose of self-improvement. The development of normal teaching activities must be guaranteed by sufficient books and materials, instruments and equipment and experimental practice bases. In practice, we find that the perfection of these conditions will have an impact on the development of teaching activities of teachers and students to a greater extent [5].

\section{Requirements for Two-way Evaluation of Pharmacy Teaching}

Teaching activities are bilateral activities between teaching and learning. Establishing Two-way evaluation of teaching activities can effectively promote the common development of teachers and students, and further improve the quality of teaching and personnel training.

\subsection{The Behavior of Guiding Students to Study Independently}

Students are the implementers of the learning process. Only when students pay attention to a certain field will they want to know more about it and regard it as a part of their daily life. Mainly through the following aspects of instructional design to guide students:

In the first class, the course objectives are defined, reading materials to be completed are listed, extracurricular tasks and completion dates are arranged, teaching plans and arrangements are distributed to students, and relevant policies on arrival, late submission or non-submission of homework are put forward. Outline on the blackboard before each class, or send handouts to students. According to the requirements of the teaching plan, write a preview report for the self-study chapters, and examine the students' self-study by checking the preview report, classroom questions and homework after class.

Let students evaluate each other, to enhance students' absorption and understanding and turn them into knowledge. Therefore, it can strengthen students' ability of literature retrieval and prescription analysis and design of pharmaceutical preparations, and can use the prescriptions collected by students as the question bank of prescription design in the final exam [6].

Based on the content of the textbook, each chapter is targeted to students with several cutting-edge and progressive articles. Through quizzes, let students know that they must take responsibility for their reading tasks, and design classroom activities to help students use the information and opinions they have learned from the materials. This will bring internal motivation to their reading.

The final exam questions are mainly flexible and applied, and they are given out from the materials that students check themselves. After the examination, give students the opportunity to evaluate the examination papers. Appropriate opportunity education, for example, when talking about preparation 
design, starts with the phrase "quality is not achieved through inspection, but given through design". Pharmaceutical production is a process management that is more important than quality standards, while learning is also a process that is more important than results.

\subsection{Implement Diversified Assessment}

It is necessary to fully mobilize different evaluation subjects to carry out teaching evaluation activities, for example, on the basis of students' teaching evaluation, combining expert evaluation, peer evaluation and teacher self-evaluation, and implementing diversified teaching evaluation. Experts and peers can use open questionnaires, instead of carrying out quantitative evaluation together with students' evaluation of teaching, they can carry out qualitative evaluation, which is not limited to the problems of questionnaires, but can be based on different evaluation objects.

\subsection{Establish an Evaluation Index System with Clear Weights}

Teachers' evaluation of learning should not be limited to those teaching factors that reflect static, easy to operate and easy to describe, but also to those dynamic, difficult to operate and difficult to quantify indicators (such as teacher-student relationship, students' creativity, learning ability, etc.) generated by the interaction of various factors. At the same time, we should not only focus on learning discipline and learning atmosphere, but also see the problems and obstacles in students' learning, and adjust teachers' teaching methods and ideas in time, to realize the real purpose of teachers' evaluation of learning and promote the common development of teachers and students [7].

\section{Implementation Process of Two-way Evaluation}

\subsection{Prepare}

\section{(1) Choose textbooks}

Methods to increase the stability of pharmaceutical preparations in pharmaceutics. This part runs through the preparation process of all preparations and is universal. Although there are many methods, there are few difficulties, and some of them have been mentioned in previous chapters. This part is very suitable for students to give lectures on stage.

(2) Heavy tasks

Divide the whole class into study group and control group. Each group is responsible for the content of a subtitle. Assign tasks to students 2 weeks in advance. Let each group discuss, find information and design blackboard writing so as to make full preparations. Whether students establish and achieve goals together with others, respect and understand other people's situations and viewpoints, and comprehensively use various communication methods for cooperation are also taken as evaluation contents.

(3) Evaluation criterion

Each group will send one student to give lectures, and the rest will be graded together with the teachers.

Diversification of evaluation contents. The total score is 100 points, and the scoring criteria are as follows.

1) Does it reflect the teaching objectives? Is the focus prominent? $30 \%$.

2) Can you give vivid examples or contact the knowledge you have learned? Is it present?

3) Scientific errors? 20\%.

4)Whether the blackboard writing is neat and clear? Do you use multimedia teaching? 20\%.

5)Is the language standard, fluent and clear? 20\%.

6)Have confidence? Are your manners elegant? 10\%.

In addition to requiring each student to grade the students who give lectures on stage, students are also required to write suggestions for the students who give lectures on stage. Students who give lectures should write a lecture experience after class. These factors of emotion, attitude and values are not involved in traditional evaluation at all. Although they do not directly participate in students' 
cognitive activities, they play a very important role in students' cognitive activities. Therefore, developmental teaching evaluation pays attention to whether students are active in learning, whether they have a correct learning attitude, whether they have a sense of discipline and innovation.

\subsection{Bidirectional Evaluation Result Analysis}

The experimental theory and skills of the two groups of students were examined respectively, and the results are shown in Table 1.

Table 1. Comparison of assessment results

\begin{tabular}{|c|c|c|c|}
\hline Group & Total number of people & Theoretical average score & Average skill score \\
\hline Research group & 20 & $91.63 \pm 5.5$ & $93.4 \pm 4.6$ \\
\hline Control group & 20 & $77.91 \pm 5.1$ & $80.2 \pm 5.4$ \\
\hline
\end{tabular}

Comparing the results of the research group with the control group with traditional teaching methods, the results are shown in Table 2. There is no obvious difference in test coverage and test difficulty. Using SPSS13.0 software, after t-test, there was a significant difference between the study group and the control group $(\mathrm{P}<0.05)$. There were also significant differences in the experimental report scores between the two groups. From the results of experimental report and test paper, it can be seen that the Two-way evaluation is superior to the traditional experimental teaching method.

Table 2. Comparison of experimental report results

\begin{tabular}{|c|c|c|c|c|}
\hline Group & $\begin{array}{c}\text { Total number of } \\
\text { people }\end{array}$ & $\begin{array}{c}\text { Average score of } \\
\text { granules }\end{array}$ & $\begin{array}{c}\text { Average score of } \\
\text { vanishing cream }\end{array}$ & $\begin{array}{c}\text { Average score of plasma } \\
\text { protein binding rate }\end{array}$ \\
\hline $\begin{array}{c}\text { Research } \\
\text { group }\end{array}$ & 20 & $96.7 \pm 5.2$ & $94.5 \pm 5.5$ & $98.4 \pm 5.8$ \\
\hline $\begin{array}{c}\text { Control } \\
\text { group }\end{array}$ & 20 & $80.2 \pm 4.1$ & $83.5 \pm 5.6$ & $83.3 \pm 5.5$ \\
\hline
\end{tabular}

In the research group, 20 questionnaires were sent and 20 were received. The results are shown in Figure 1:

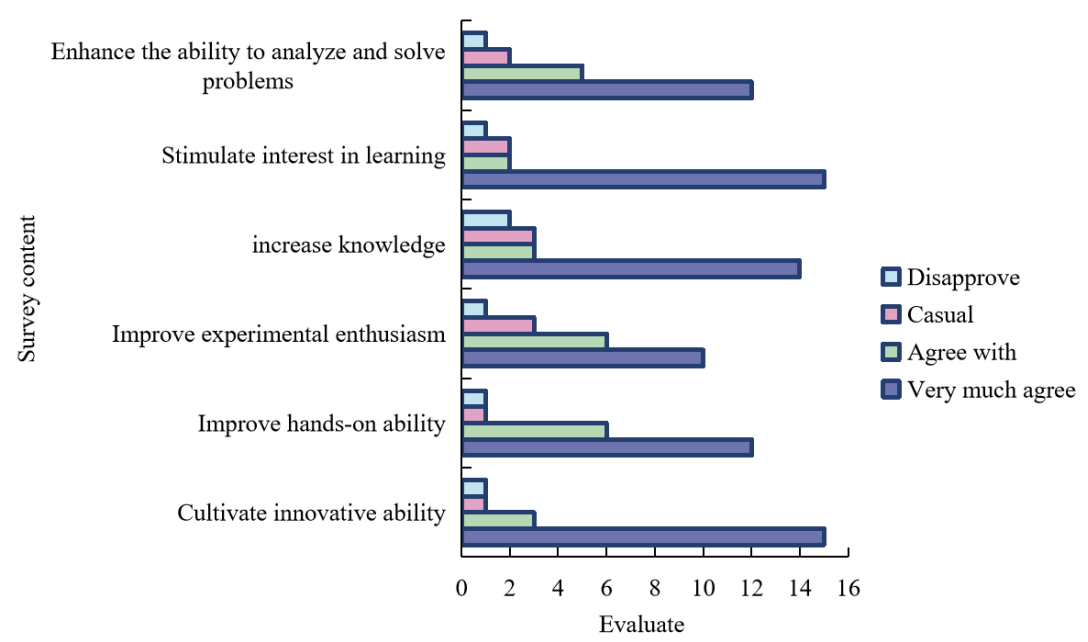

Figure 1. Students' evaluation of teachers' teaching methods 


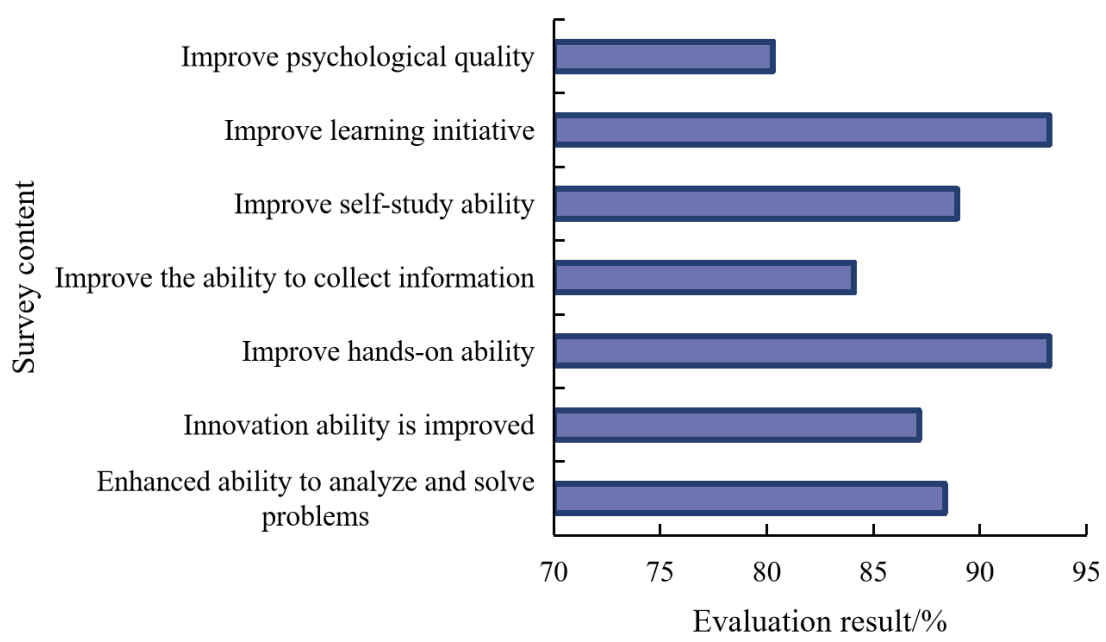

Figure 2. Teachers' evaluation of students' learning effect

From the above results, it can be seen that most students think that inquiry-based classroom teaching can stimulate learning interest, improve scientific research ability, thinking ability, innovation ability and team cooperation spirit, which is an effective and good method.

Two-way evaluation of pharmacy teaching is helpful to improve students' learning effect, and most students think that their hands-on ability, ability to analyze and solve problems have been greatly improved. The enthusiasm and initiative of participating in experimental teaching are improved, the attendance rate of experimental classes reaches $100 \%$, and the number and times of students actively discussing experimental problems with teachers are greatly increased. Students' ability to use knowledge comprehensively has been enhanced. The examination scores of students in the study group were significantly higher than those in the control group, and the difference was statistically significant $(\mathrm{P}<0.05)$.

Two-way evaluation of pharmacy teaching focuses on students as the main body, scientific inquiry, practice and innovation, sustainable development, the cultivation of scientific inquiry methods, and the cultivation of students' self-study ability, ability to analyze and solve problems, ability to study and innovation consciousness. Pay more attention to methods and processes, and highlight practice and innovation. The application of Two-way evaluation can change the present situation of boring classroom teaching machinery, make the classroom full of vitality, and make both teachers and students in a "partner" relationship of democracy, equality, freedom, tolerance, encouragement and help, thus truly correcting the dominant position of teachers and the dominant position of students in the teaching process, and making classroom teaching achieve the desired effect.

\section{Summary}

The traditional view of education quality is a view of knowledge quality, which evaluates the teaching quality by the amount and depth of knowledge mastered by college students. The development of the times requires us to change the traditional knowledge quality view and the once popular ability quality view into a comprehensive quality view including knowledge and ability. Through the above improvement in teaching, combined with the results of students' questionnaire survey, students' interviews and usual quizzes, it shows that students are generally interested in pharmacy courses, and the learning effect is good. During the implementation of the Two-way evaluation of pharmacy teaching with students as the main body, students can actively complete the learning tasks, and the workload of teachers has not increased to a great extent, which is suitable for further popularization and application in other courses. 


\section{References}

[1] Jing Wong, Zhao zhongbo, Guo dongyan, et al. the practice of "Student-centered" teaching philosophy in the teaching of pharmacy of traditional Chinese medicine [J]. journal of Shaanxi university of traditional Chinese medicine, 2019, 000(005): P.116-119.

[2] Huang Mei. Practice and research on teaching method reform of pharmacy [J]. China Health Nutrition, 2020, 030(021):44.

[3] Liang Yangang, Li Renjie. Student-centered teaching quality evaluation of postgraduate courses [J]. 2021 (2013-4):52-54.

[4] Wang Binghui, Yang Juntao. Analysis of the role and evaluation of classroom assessment in the teaching of Pharmacy [J]. Science and Technology Innovation Herald, 2020, 017(006):182-183.

[5] Ge Jian, Lin Fang, Deng Tongle, et al. A preliminary study on the curriculum reform of "Biopharmaceutics and Pharmacokinetics" under the background of inquiry teaching and extracurricular scientific and technological activities [J]. Science and Education Guide-Electronic Edition (first half), 2019, 000(012):104-105.

[6] Zhang Lei, Chen Qiu, Mao Dongdong, et al. Exploration and practice of Pharmacy teaching based on OBE mode [J]. Journal of Higher Education, 2019, 000(023):139-140,144.

[7] Li yunwei. on the application of formative assessment in pharmacy teaching [J]. modernization of education, 2019, v.6(89):35-36. 